\title{
Exit Strategy from COVID-19: Vaccination and Alternate Solution
}

\author{
Indrani Roy ${ }^{(凶)}(\mathbb{D}$ \\ IRDR, University College London (UCL), London, UK \\ indrani.roy@ucl.ac.uk, indrani_r@hotmail.com
}

\begin{abstract}
Vaccination groups all over the globe made a strong coordinated effort to put an end to the current COVID-19 crisis. Since vaccination started first in the UK on $8^{\text {th }}$ December 2020, we have sufficient data to analyze and derive useful results. It addressed issues viz. seasonality, indirect consequences of mass vaccination and fast mutation of the virus after mass vaccination. To develop useful timely insights, some similarities between COVID-19 and Flu received attention. Critical and open analyses, balanced discussion in the current crucial stage are desperately needed. Questioning, debating and criticism are always the basis of good science and the main pillars to its advancement. With that objective in mind, it is an effort to explore areas relating to the effectiveness of COVID19 vaccines with a pragmatic viewpoint. Policymakers will be greatly benefitted from such analyses. An alternative optimistic pathway is also mentioned which was proposed as early as $17^{\text {th }}$ March 2020 and is practically without side effects and no vested interest involved.
\end{abstract}

Keywords: COVID-19 $\cdot$ Temperature $\cdot$ Exit strategy $\cdot$ Solution $\cdot$ Seasonality · Mass vaccination

This analysis explores few important aspects of current COVID-19 situations from pragmatic viewpoints. In this context, an alternate optimistic pathway is also discussed.

\section{Effects of Lockdown vs. Vaccination vs. Seasonality}

In winter, many countries showed a sudden surge. After the imposition of strict lockdown, surges are likely to be reduced. Moreover, different countries started vaccination at different time of the winter; some started early winter e.g. the UK ( $8^{\text {th }}$ December 2020 [1]) whereas, some started late e.g. South Africa ( $17^{\text {th }}$ February 2021 [2]). It is beneficial to study the effects of Lockdown vs. Vaccination vs. Seasonality in various countries.

For UK and Israel, the 2nd peak was much stronger than the first one (Fig. 1). For both countries, the second peak occurred after vaccination started. South Africa did not start vaccination till $17^{\text {th }}$ February, but the 2 nd wave peaked same time with the UK and Israel (around mid-January). Not only that but also the 2nd wave was falling

Electronic supplementary material The online version of this chapter (https://doi.org/10.1007/ 978-3-030-88163-4_38) contains supplementary material, which is available to authorized users. 
much faster than UK and Israel upto $17^{\text {th }}$ February [2] (Fig. 1). Even for the UK and Israel, where massive vaccination took place, the total deaths in the three months after vaccination (also had strict lockdown), reached the overall death of the past 10 months before vaccination [2].

The UK had much higher vaccination than any other EU country. Also, the UK showed the highest daily Deaths than any other EU country [3, see 7-day average till $28^{\text {th }}$ February]. The UK had a strict lockdown and as expected Death is decreasing in late winter (Fig. 2).

A success story on vaccination in Israel attracted global attention [4]. However, a study [5] authored by Dr Hervé Seligmann, a scientist from the Faculty of Medicine, Aix-Marseille University, France who is of Israeli-Luxembourg nationality rejected the success story that claimed Israel could be a role model. That study raised issues towards unsubstantiated claims and biased analyses and suggested a mismatch between data published by authorities with the observed reality. It explored how after vaccination started, the overall outcome of the health situation in Israel deteriorated in various respects.

UAE had much high vaccination and it started on 14th Dec, 2020 [6]. Some days after the start of vaccination, there is a very steep rise in Cases and thereafter a steep rise in Deaths (Fig. 3). Similar surges are noticed for India, Brazil, Bangladesh and Pakistan among others [3]. Globally, Cases and Deaths started increasing after 5 weeks of a steady decline [3] and coincidentally, the period of recent rise matches when major
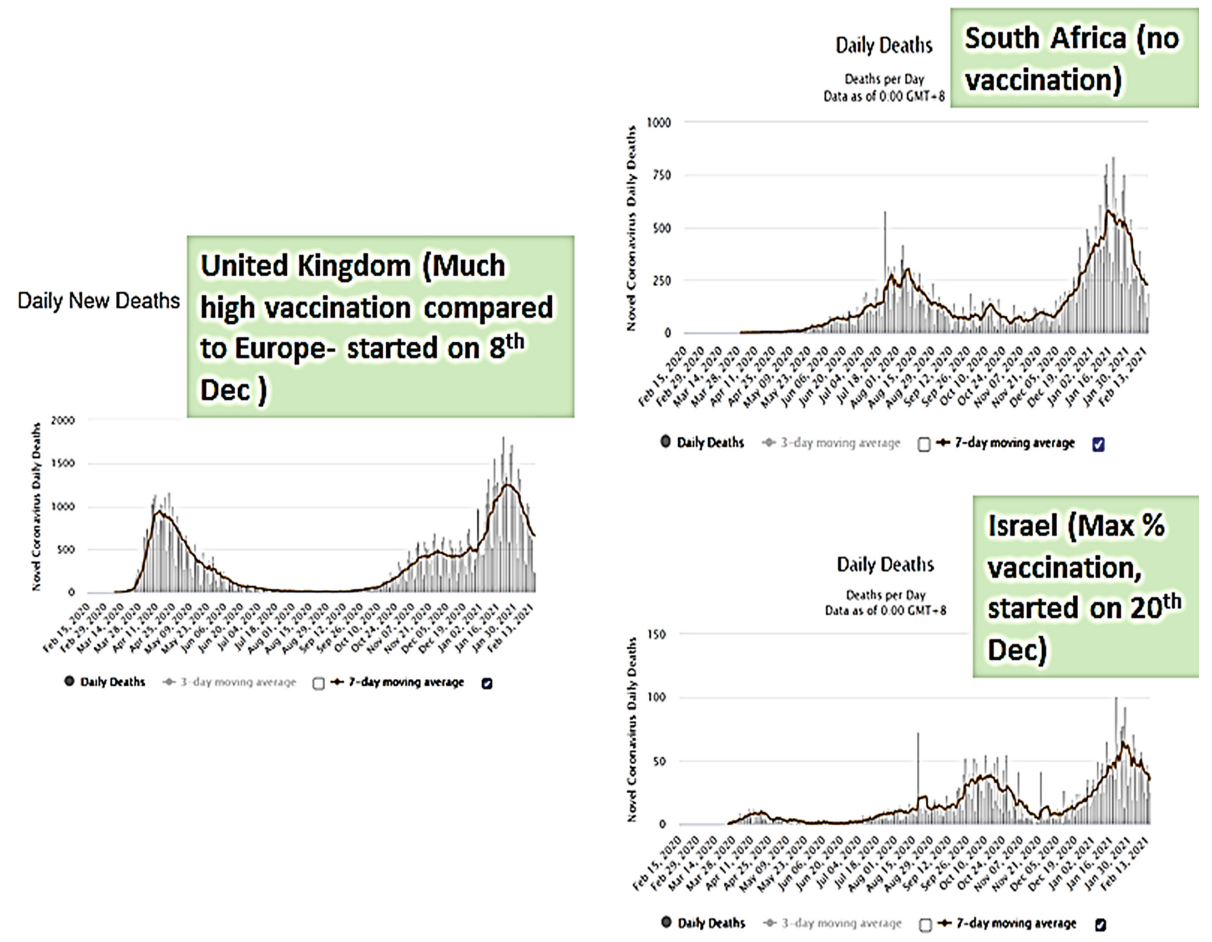

Fig. 1. Daily new Deaths for UK, Israel and South Africa before South Africa started the vaccination programme (on 17/02/21). The seven-day moving average is marked by a thick line. (https:// www.worldometers.info/coronavirus/country/, accessed on 17/02/2021) 
vaccinations programme was initiated worldwide. A highly populated country India was having a steady decrease for five months. India did not have any lockdown. Though neighbouring countries Pakistan and Bangladesh experienced the $2^{\text {nd }}$ wave this winter but India did not. India passed major festive seasons where social distancing was very difficult to be maintained, still cases and deaths continued to decline. There is a sudden reversal in the trend of cases and deaths in India, from declining to rising, within a month after the start of vaccination.

a)

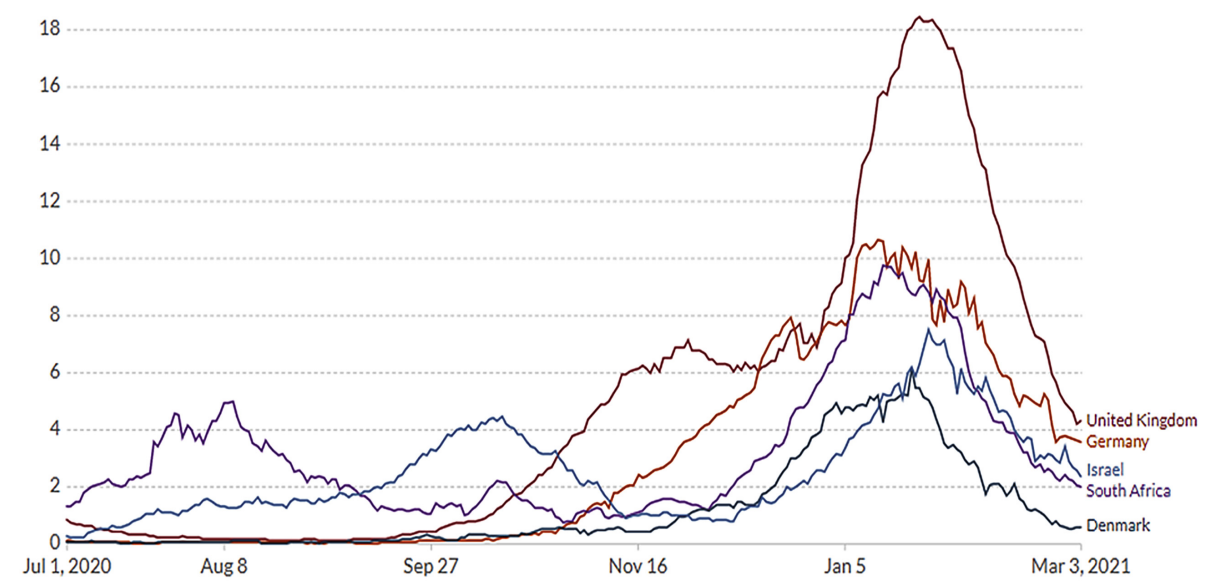

b)

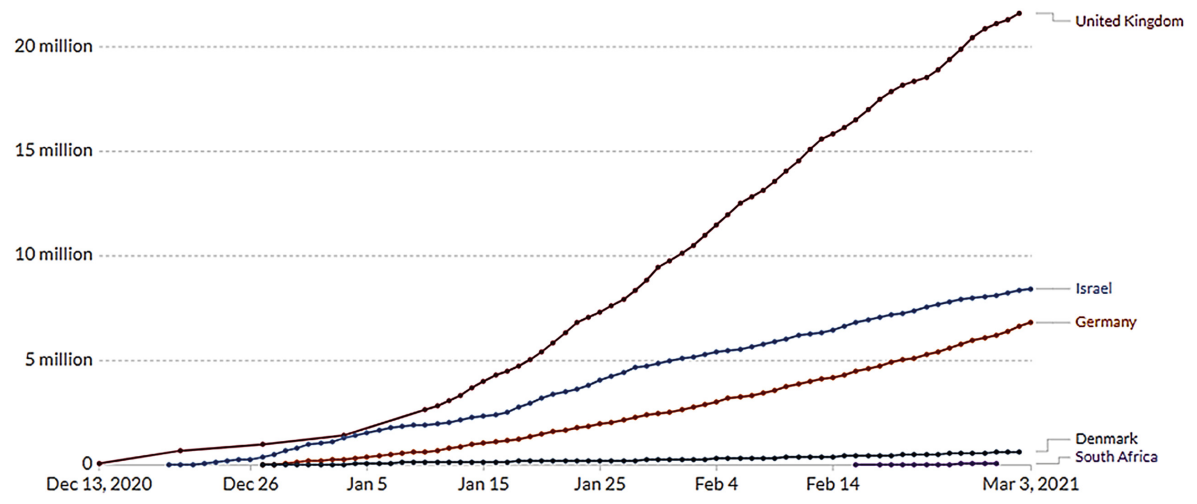

Fig. 2. Deaths of Covid-19 and Vaccination data of few selective countries, where Deaths peaked in winter. a) daily new confirmed Deaths per million in rolling 7-day average, b) cumulative COVID vaccination dose. Israel and UK had the highest vaccination though daily Deaths are still higher at the beginning of March. South Africa practically did have nominal vaccination, but the daily Death though peaked higher than Israel but falling at a much faster pace and even lower than Israel. Source: [https://ourworldindata.org/coronavirus-data-explorer]. 
a)

Daily New Cases in the United Arab Emirates

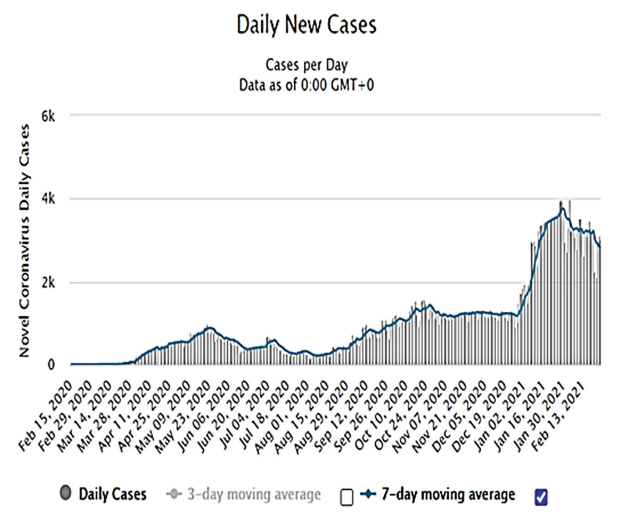

b)

Daily New Deaths in the United Arab Emirates

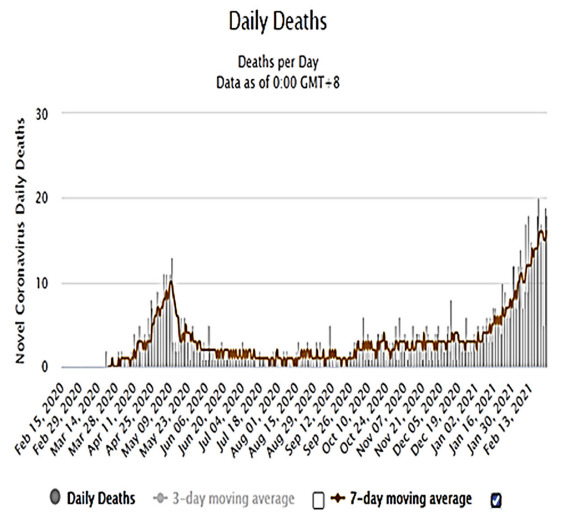

Fig. 3. Daily new Cases (a) and Deaths (b) for the United Arab Emirates (UAE). Seven-day moving averages are marked by coloured thick lines. Vaccination programme started on 14th December [6]. Source: (https://www.worldometers.info/coronavirus/country/united-arab-emirates/)

Thus, it could be of interest to check which country showed a decrease after the vaccination started, eliminating the effect of lockdown and seasonality.

\section{Reporting of Short-Term Adverse Effects After Vaccination}

In the short time frame of clinical trials, there are hardly any possibilities to test the medium and long-term adverse effects. Even for the short term, only few thousand people took part in trials among which half were given Placebo. Many complicated interactions among various underlying health issues are likely to be missed and could not be tested due to the small sample size.

For short term adverse effects, recent data also raised questions [7]. In the United States, a total of 1136 individuals have died till $26^{\text {th }}$ February after receiving mRNA vaccines for COVID-19. A total of 587 (51.7 percent) died within a week; among those who died, 94 ( 8.3 percent) died on the same day, 150 (13.2 percent) died the day after, 105 died 2 days after, and 68 within 3 days [7, 8]. More recent record upto April 5, 2021 shows VAERS received 2,794 reports of death among vaccinated people [9]. Cardiac arrest was one of the main causes of death; whereas, blood clots, anaphylaxis, temporary facial paralysis and Bell's palsy were reported among the majority of other critical patients. It would be advisable to track all these vaccinated people afterwards and to note if they were affected by any of those particular diseases in later stages or not. Also, a monitoring system could be proposed to check if deaths caused due to some of those specific symptoms/diseases exceeds normal count or not in the coming months. Such anomaly counts of death or symptom could give some ideas of medium and long-term side effects, if any, due to vaccination. 
A comparison between deaths after Influenza (Flu) and COVID vaccine from VAERS reports gives useful information. For Flu vaccine in 2019 influenza season, a total of 45 deaths occurred which is 0.0000265 percent of total vaccination. Whereas, for the COVID vaccine, a total of 1136 deaths are reported as of Feb. 26, which is approximately a rate of .0024 percent, a 100-fold higher than reported deaths after the Flu vaccine [8].

In India as of March 29, around 180 people have died and 617 had serious adverse events following vaccination, according to the Adverse Events Following Immunisation (AEFI) committee, the main government reporting centre [10]. A major proportion of deaths occurred less than three days after the vaccination and major causes of deaths are noted as Acute Coronary Syndrome/Myocardial Infarction. Authorities say Deaths are unrelated to the vaccine. In the UK, the Medicines and Healthcare products Regulatory Agency (MHRA), a govt organisation reported that upto March 31, there are 79 reports of blood clots accompanied by low blood platelet count. A total of 19 people died, of those three were under the age of 30 [11]. Currently, it is concluded that clotting syndrome should be listed as a very rare side-effect of one of the vaccines, Oxford/AstraZeneca jab [11].

\section{Importance of Healthy Peer-review and Service to Humanity}

Constructive criticism, healthy peer review are always the pillars of good science, which became more important when the lives of billions of people are involved. Healthy open peer-review from qualified scientists and experts from various disciplines are likely to dismantle many unsorted puzzles and now urgently required. It is such an important step and enough scrutiny in every step is indeed expected.

Experts, scientists raised various sensible questions on several platforms e.g., questions on mRNA technique, the trial process for understanding medium and long-term effects etc. among others. Those are very important steps and need to have complied with when millions of people are vaccinated on a regular basis. It is pointed out that COVID-19 vaccine trials and 'studies seem designed to answer the easiest question in the least amount of time, not the most clinically relevant questions' [12, 13]. Studies also discussed that current trials aren't designed to tell whether covid-19 vaccines can save lives [13, Table 1]. The frail elderly are disproportionately contributing to the serious cases of the disease, yet in the randomized trials, they were insufficiently recruited [14]. In the end, it should not be the media that will control and lead science. Prof Fiona Godlee, editor in chief, BMJ made a very valuable comment in this regard, "Science by press release" is just one of many flaws in the way new treatments are evaluated, brought into stark relief by the pandemic' [15]. Fabricated analyses and biased results should not be on the headline in everyday news; whereas, many important research/analyses will be suppressed. Those areas need to be addressed/monitored and brought to the knowledge of respective authorities in various steps of decision making. We need to analyse the whole situation to take a timely intervention, we need to ask whether the intervention with vaccines is making situations better or worse, whether we have more and more liberty to accept excuses when the solution does not work. With fixed world resources, the proposition of vaccinating billions and billions of people every six months times raises a very obvious question, whether such an effort is worth it and essential. The direct and indirect cost of that strategy needs attention so as the effectiveness of such a strategy. 
As there are huge vested interests involved for vaccine and allied businesses, long chains of beneficiaries are linked, additional precautions should be in place. Ethics and integrity should not be compromised in that novel goal of saving humanity. One proposition in that direction could be producing and distributing vaccines on a not-forprofit basis.

It could be very welcoming coordinated initiatives from all vaccine groups and will be highly appreciated and valued.

Table 1. Characteristics of ongoing phase III covid-19 vaccine trials.

\begin{tabular}{|c|c|c|c|c|c|c|c|}
\hline & Moderna & Pfizer & $\begin{array}{l}\text { AstraZeneca } \\
\text { (US) }\end{array}$ & $\begin{array}{l}\text { AstraZeneca } \\
\text { (UK) }\end{array}$ & Janssen & Sinopharm $^{*}$ & Sinovac \\
\hline Vaccine name & mRNA-1273 & BNT162 & AZD1222 & AZD1222 & Ad26.COV2.S & $\begin{array}{l}\text { Sinopharm } \\
\text { vaccine }\end{array}$ & $\begin{array}{c}\text { Sinovac } \\
\text { CoronaVac }\end{array}$ \\
\hline Registration No & NCT04470427 & NCT04368728 & NCT04516746 & $\begin{array}{c}\text { NCT04400838 } \\
\text { (UK), } \\
\text { NCT04536051 } \\
\text { (Brazil), } \\
\text { NCT04444674 } \\
\text { (South Africa) }\end{array}$ & NCT04505722 & NCT04510207 & NCT04456595 \\
\hline Target enrolment & 30000 & 43998 & 30000 & 19330 & 60000 & 45000 & 8870 \\
\hline Ages eligible & $18+$ & $12+$ & $18+$ & $5-12,18+$ & $18+$ & $18+$ & $18+$ \\
\hline $\begin{array}{l}\text { Protocol publicly } \\
\text { available }\end{array}$ & Y & Y & Y & $\mathrm{N}^{\dagger}$ & Y & $\mathrm{N}$ & $\mathrm{N}$ \\
\hline \multicolumn{8}{|c|}{ Notable excluded populations: } \\
\hline $\begin{array}{l}\text { Children and } \\
\text { adolescents }\end{array}$ & Excluded & Many excluded & Excluded & $\begin{array}{c}13-17 \\
\text { excluded }\end{array}$ & Excluded & Excluded & Excluded \\
\hline $\begin{array}{l}\text { Immunocompromised } \\
\text { patients }\end{array}$ & Excluded & Excluded & Excluded & Excluded & Excluded & Excluded & Excluded \\
\hline $\begin{array}{l}\text { Pregnant or } \\
\text { breastfeeding women }\end{array}$ & Excluded & Excluded & Excluded & Excluded & Excluded & Excluded & Excluded \\
\hline \multicolumn{8}{|c|}{ Endpoints undergoing formal study ${ }^{\mp}$ : } \\
\hline $\begin{array}{l}\text { Prevention of } \\
\text { symptomatic disease } \\
\text { in vaccine recipient }\end{array}$ & $\mathrm{Y}$ & Y & Y & Y & Y & Presumably ${ }^{\S}$ & Y \\
\hline $\begin{array}{l}\text { Reduction in severe } \\
\text { covid-19 (hospital } \\
\text { admission, ICU, or } \\
\text { death) }\end{array}$ & $\mathrm{N}$ & $\mathrm{N}$ & $\mathrm{N}$ & $\mathrm{N}^{\mathbb{\|}}$ & $\mathrm{N}$ & $\mathrm{N}$ & $\mathrm{N}$ \\
\hline $\begin{array}{l}\text { Interruption of } \\
\text { transmission (person } \\
\text { to person spread) }\end{array}$ & $\mathrm{N}$ & $\mathrm{N}$ & $\mathrm{N}$ & $\mathrm{N}$ & $\mathrm{N}$ & $\mathrm{N}$ & $\mathrm{N}$ \\
\hline
\end{tabular}

[after Doshi P, 2020 [13], see, details there, used with copyright permission]

\section{Similarities Between Influenza and COVID-19}

There are still not any vaccines for many diseases, e.g. AIDS etc. Hence a balanced media coverage, focus on varied medical research or remedy on COVID-19 other than the vaccine is equally important. 
Every winter, tens of thousands of people die in the UK, Europe and northern America from Influenza (Flu), a virus-borne respiratory disease. Centers for Disease Control and Prevention (CDC) estimated 61,000 deaths in the United States during 2017-2018 from influenza, which was higher than any season since 2009 [16]. At the beginning of every winter, people mainly from old and vulnerable groups are vaccinated against Flu virus; but still, it is not yet been possible to eradicate Flu. On the contrary, it became more powerful and destructive in later years. The main reason is that the virus is mutating over time and space. Hence the question arises could it be similar for COVID-19? There are many similarities between these two virus-borne respiratory diseases COVID-19 and Flu.

Few resemblances were noted from the web [17]: 'flu season occurs in the fall and winter. In the U.S., that means October-March, and in the southern hemisphere, JuneSeptember. Although the reason for this seasonality is not entirely understood, influenza virus has been shown to survive longer at low temperatures and low humidity. Other suggested explanations include weakened host immunity due to decreased sunlight and vitamin D and increased exposure to the virus due to indoor cohabitation in the winter.'

Other relevant facts and observations:

- Both the viruses are mutating over time and space. Many new strains of COVID-19 are emerging over time [18]. Since the first vaccine came up only in December 2020, many new variants are already detected in the next three months which are ineffective to the vaccine $[19,20]$. One comment from journal the Lancet, 'rapid regulatory approval and roll-out of several vaccines have ignited much optimism. However, this optimism has been dampened by the emergence of several new virus variants that are more transmissible and less sensitive to vaccine-induced antibodies [20].

- There are many dissimilarities between COVID-19 with other vaccines (polio, smallpox etc.) too; e.g., unlike other vaccines, if people are vaccinated for COVID-19, they still can get the disease, can transmit it and even die from it [10, 21]. Even after 15 days of the second dose, people can be a carrier of the disease [10]. In Michigan, 246 breakthrough Covid-19 cases have occurred after the $2^{\text {nd }}$ dose, which resulted in 11 hospitalizations and even three deaths [21]. 'Breakthrough cases,' happen when at least 14 days after receiving the final dose of the vaccine people test positive.

- Like Flu, during summer the situation improved in Europe and North America. Last summer, in Europe, deaths from COVID-19 were practically nil without any vaccine. People vaccinated in March 2021 for COVID-19, will require to be vaccinated again after six months i.e., before the next winter. This is because the immunity to the disease is expected to reduce after six months [22]. Whether the same vaccine will work or not that time will be another issue. Following our past experience with the Flu vaccine, it can be speculated beforehand.

There could be relevance to this discussion to Flu vaccine ineffectiveness in excess of 50,100 deaths in the UK and EU in 2017-18 [23]. Deaths were highest in more than 40 years, though many vaccines were evolved and modified during that last 40 years. 'The Office for National Statistics said flu and the ineffectiveness of the flu vaccine were key reasons for the rise of excess winter deaths in 2017-18' [23]. Even for 2016, the rise in deaths in England and Wales for the previous 12 years, was attributed 
to the failure to provide an effective Flu vaccine, government's public health agency had admitted [24]. Those records indicated how poorly Flu vaccines performed in recent periods compared to the past.

\section{New Variants and Fast Mutation}

An inspiring initiative was taken to develop a COVID-19 virus mutation tracker, which is immensely beneficial to monitor the progression of mutated variants $[18,25]$. It gives an idea of how rapidly it can mutate over temporal and spatial scales [Fig. 4]. The fingerprints reveal the route of virus transmission so as timelines of different mutations. For the UK, till 03/03/21 the number of unique variants identified as 11,098, of which local variants 10,7038 and foreign variants 3,066 [18]. Interestingly, the timeline of new variants suggests a sudden increase in mutation since December 2020 [18] (Fig. 4b), the time when major vaccination programme was initiated. Prior to that in the last 11 months, upto November 2020, the progression was really slow in comparison (see the numbers in Fig. 4b).

Vaccines themselves can drive viral mutations and hence COVID-19 vaccines can add fuel to the evolution of mutation of Coronavirus as suggested by Professor Paul Bieniasz from Rockefeller University, USA [26]. Those may explain why there is a surge in the number of mutated variants, so as cases globally after the mass vaccination started.

\section{Mass Vaccination and Transmission - Trial Experiments}

Trial experiments and protocols set for COVID-19 vaccination did not take into consideration of many direct and indirect consequences of mass vaccination.

Apart from looking into details of direct side effects after vaccination, the secondary effect that might be caused after mass vaccination needs attention too. Here is a trial experiment that showed vaccinated people can spread the disease and they can be carrier even after 15 days of $2^{\text {nd }}$ dose.

Asymptomatic cases also have role in the transmission and spread of SARS-CoV2 infections [27]. Some clinical trial experiments are conducted among vaccinated healthcare workers in the US, that also allowed for increased detection of asymptomatic infections [28]. Among vaccinated people, 14,604 were monitored in trials and out of which 379 tested positive at least 1 day after vaccination. The majority $(71 \%)$ were tested positive within the first 2 weeks after the first vaccination. Whereas, 37 health care workers were tested positive after receiving both doses and 22 had positive test results 1 to 7 days after the second dose. Only 7 tested positive 15 or more days after the second dose [Table $2,28]$. This study indicated that after vaccination, the absolute risks of testing positive for SARS-CoV-2 are higher than the risks noted in original phase III trial experiments. Vaccinated, over-confident people, if asymptomatic or develop mild symptoms, can act as super-spreaders.

Such analyses may raise major worries for developing countries like India and most countries of African continents where deaths per million were practically very less in comparison to developed countries prior to mass vaccination. It may explain why highly 
(a)

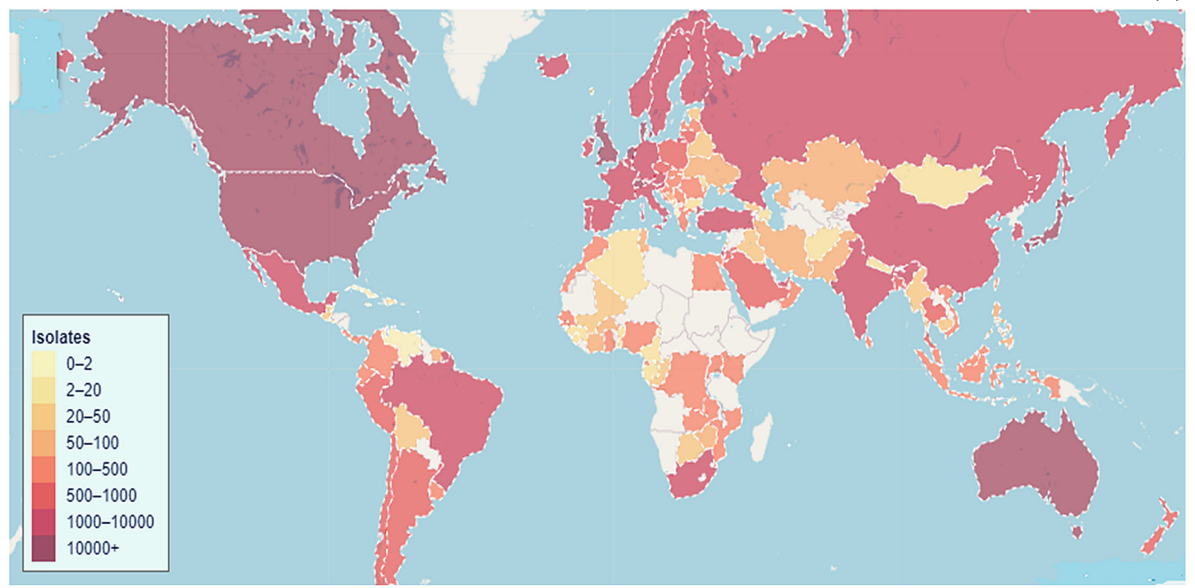

(b)

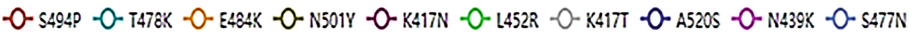

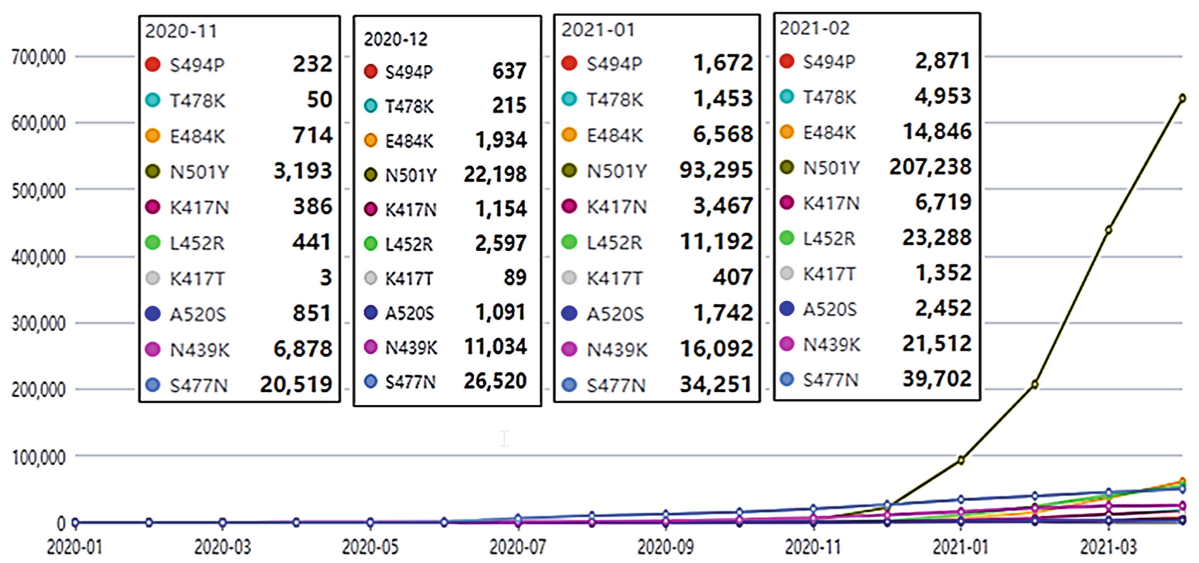

Fig. 4. COVID-19 virus genome isolates from patients are being regularly sequenced worldwide and continuously updated; for each sample, there is an accession number. The spatial distribution patterns (a) and temporal patterns (b) are presented. b) shows the top 10 major virus mutations timelines which are progressing at a very rapid scale since December, 2020. Numbers in each month from November to February are shown in the top left box and shows how slow was the pace, in comparison, upto November, 2020. [https://www.cbrc.kaust.edu.sa/covmt/, Accessed on 03/03/2021 (a) and 1/04/2021(b) respectively].

populated countries like Brazil and India are worst affected as very high number of people are vaccinated in a short space of time. Brazil started vaccination at around mid-February and just after a month a very steep rise in deaths is noticed [2]. A highly populated country India was about to control the disease without any vaccine or lockdown, but since the middle of February (vaccination started on $16^{\text {th }}$ January, [2]) was showing a sudden 
surge in transmission, raising major concerns. Such a steep rise in deaths and cases for Brazil and India never happened in the entire period of the pandemic [3].

Such analyses raise few questions that need in-depth investigation and could have been attended before any rapid mass vaccination drive: i) is vaccine causing more mutation of virus? ii) if true, can more different vaccines can create more forms of mutations? iii) if vaccines have roles on viral mutation, is it dependent on climate, various genetic groups of people and ethnic groups, past health conditions of individuals etc.? iv) in some countries reduction of vaccination doses and imposition of lockdown, could abate the uncontrolled rate of transmission (e.g., India in May 2021, [3]). Such timely intervention indicated do the government and policy makers have the control on transmission rate of the virus by varying the number of vaccine doses, temporally as well as spatially? Can the timing and severity of global third/forth and other waves in future be controlled by regulating vaccine doses? v) Professor Paul Bieniasz mentioned, the time between initial vaccination and the time of second shot to maximize the immune response might serve as a sort of breeding ground for the virus to acquire new mutations

Table 2. New SARS-CoV-2 infections among vaccinated health care workers from December 16, 2020, through February 9, 2021.

\begin{tabular}{|c|c|c|c|}
\hline \multirow[t]{3}{*}{$\begin{array}{l}\text { Days after } \\
\text { Vaccination }\end{array}$} & \multicolumn{3}{|c|}{ Vaccinated Persons } \\
\hline & $\begin{array}{l}\text { With New Infection } \\
\qquad(\mathrm{N}=379)\end{array}$ & $\begin{array}{l}\text { Tested } \\
(\mathrm{N}=14,604)^{*}\end{array}$ & $\begin{array}{l}\text { Eligible for Testing } \\
\qquad(\mathrm{N}=36,659)+\end{array}$ \\
\hline & Number & & number (percent) \\
\hline \multicolumn{4}{|l|}{ Dose 1} \\
\hline Days 1-7 & 145 & 5794 & $35,673(97.3)$ \\
\hline Days 8-14 & 125 & 7844 & $34,404(93.8)$ \\
\hline Days $15-21$ & 57 & 7958 & $32,667(89.1)$ \\
\hline $\begin{array}{l}\text { Day } 22 \text { or later, } \\
\text { Before dose } 2\end{array}$ & 15 & 4286 & $32,327(88.2)$ \\
\hline \multicolumn{4}{|l|}{ Dose 2} \\
\hline Days 1-7 & 22 & 5546 & $23,100(63.0)$ \\
\hline Days 8-14 & 8 & 4909 & $16,082(43.9)$ \\
\hline Days 15 or later & 7 & 4167 & $14,990(40.9)$ \\
\hline
\end{tabular}


[26]. vi) if vaccine can cause mutation, it is not only traveling that can spread the mutated virus from country to country or regionally; it can equally happen within any community sooner or later, even if, there is a strict travel ban or lockdown. vii) At the beginning of winter 2021, like Flu, there is another surge likely to happen in Europe and the northern US. It is very likely that we are going to blame new mutant variants and another lockdown will be impending. Thus, we need not be optimistic or pessimistic but Pragmatic. We need to explore alternate pathways side by side and be well-prepared with substitute solutions beforehand (to mention a few [29-31]).

Furthermore, it is worth mentioning that without proper checking of all direct and indirect effects of mass vaccination, any hasty steps can cause more harm than good. It can lead to severe consequences to highly populated countries that we eye witnessed recently. Those areas need thorough investigation and urgent attention on time to stop further escalation of a worsening situation.

\section{Seasonality and COVID-19}

Seasonal effects should be considered very important for the transmission of COVID19. By around mid-April last winter, almost all European countries and countries from the northern USA showed a decline in transmission without any intervention of vaccines. Like Flu, transmission in fact was nominal during mid-June to September 2020, compared to the severity of other months. It would have been also expected likewise from mid-April this year, if vaccines were not in place. After major vaccination started there were surges in transmission in almost all countries and most countries had to impose strict lockdown conditions. It would be of interest to monitor how the effect of vaccine, (including the proportion of vaccinated percentage, time of major vaccination programme) override the effect of seasonality in various European countries and countries of northern US.

A recent systematic review work of several papers found almost all studies detected that temperature played a huge role in the transmission of the virus [32]. However, authors finally concluded that certainty of the evidence was graded as low, which is based on their (Table 3 [32]). A careful observation suggests that 'low' grading was not supported by their Table. On the contrary, it is completely the other way round. The area of seasonality, the dependence of seasonal temperature, though was very evident throughout, till vaccination started [29-31, 33], but surprisingly undermined by the scientific community and in many important publications.

Then the question is why? Could it be due to the previous experience with the Seasonal Flu Vaccine?

\section{Optimism with Alternative Pathways}

Studies explored whether the global temperature had any role in the spread and vulnerability to COVID-19 [29-31] and highlighted that global temperature played an important role in transmitting the virus. The risk from the virus was reduced significantly for warm 
places and countries; whereas, a moderately cool environment was the most favourable state. Various degrees of vulnerability were identified based on the temperature of March and April and countries were specified. It was shown countries can even switch from one state of vulnerability to another following the variability of temperature and that knowledge can be used for planning country-wise mitigation strategies [29-31]. Interestingly, the dependency of temperature on the global spread of the disease was consistent throughout before the vaccination drive, though deviated after initiation of mass vaccination programme on a global scale [2].

The dependency of temperature is true for similar generic category Coronavirus SARS (Severe Acute Respiratory Syndrome) and MERS (Middle East Respiratory Syndrome) $([34,35])$ and also true for other similar seasonal air-borne Flu viruses [36]. The virus remains active for a long time in low temperatures [34] and low temperature significantly contributes to its survival and transmission $([35,37,38])$. A study using seasonally dependent endemic virus [36] showed when the temperature is $5^{\circ} \mathrm{C}$ and relative humidity between (35 to 50)\%, the infection rate was very high (75-100\%); whereas, when relative humidity was still kept at $35 \%$, but only the temperature was increased to $30{ }^{\circ} \mathrm{C}$, the infection rate was surprisingly reduced to zero.

\section{Solutions : General Measures}

- Using Sauna facilities: Usually hotels, gyms, leisure centres contain existing Sauna facilities. Also, mobile and Caravan Sauna facilities can be thought of in future. After Sauna, if surfaces in public places are touched, hand washing is advisable.

- Portable Convector Room Heater: Stay close to a convector room heater and inhale hot air at least two times a day for around half an hour each time (keeping comfort level). It would be very useful at the initial stages of the disease.

- Disinfect any place using High Temperature: Before start of office, school or business, temperature of premises may be kept very high, (say, $60^{\circ} \mathrm{C}$ ) for half an hour. For airports, train and bus, the same method of disinfecting could be thought of. Optimum temperature and duration can be tested easily. For any external object or material, disinfecting using high temperature could be a useful solution.

- Using Blow Dryer/ Hair Dryer: For minor symptoms, inhaling hot air intermittently through the nose (keeping comfort level) even for five minutes, say two/three times a day, will also be useful to kill virus in the nasal cavity.

- Hot Drinks: For very mild symptoms, take hot drinks (could be tea, coffee, warm milk, hot water with lemon etc.) few times a day to destroy virus in the mouth and throat. Gargle with warm salt water at least three/four times a day will be very beneficial. Hot soup will also be useful.

Why: The virus is very sensitive to Temperature. It mainly
enters through the Nose (WHO). Testing is done with swabs
from the nasal cavity and the back of the Mouth.
Important: Only even Convector Room Heater and Hot Salt
Water gargle, Hot Drinks can serve the main purpose.

Fig. 5. Heat-based general measures at initial stages of the disease. (Roy, 2020, [29-31])

A laboratory experiment with similar generic Coronavirus (viz. SARS-CoV) using a variable temperature [37] showed inactivation of the virus was faster at all humidity 


\section{Solutions: The virus is very sensitive to Temperature}

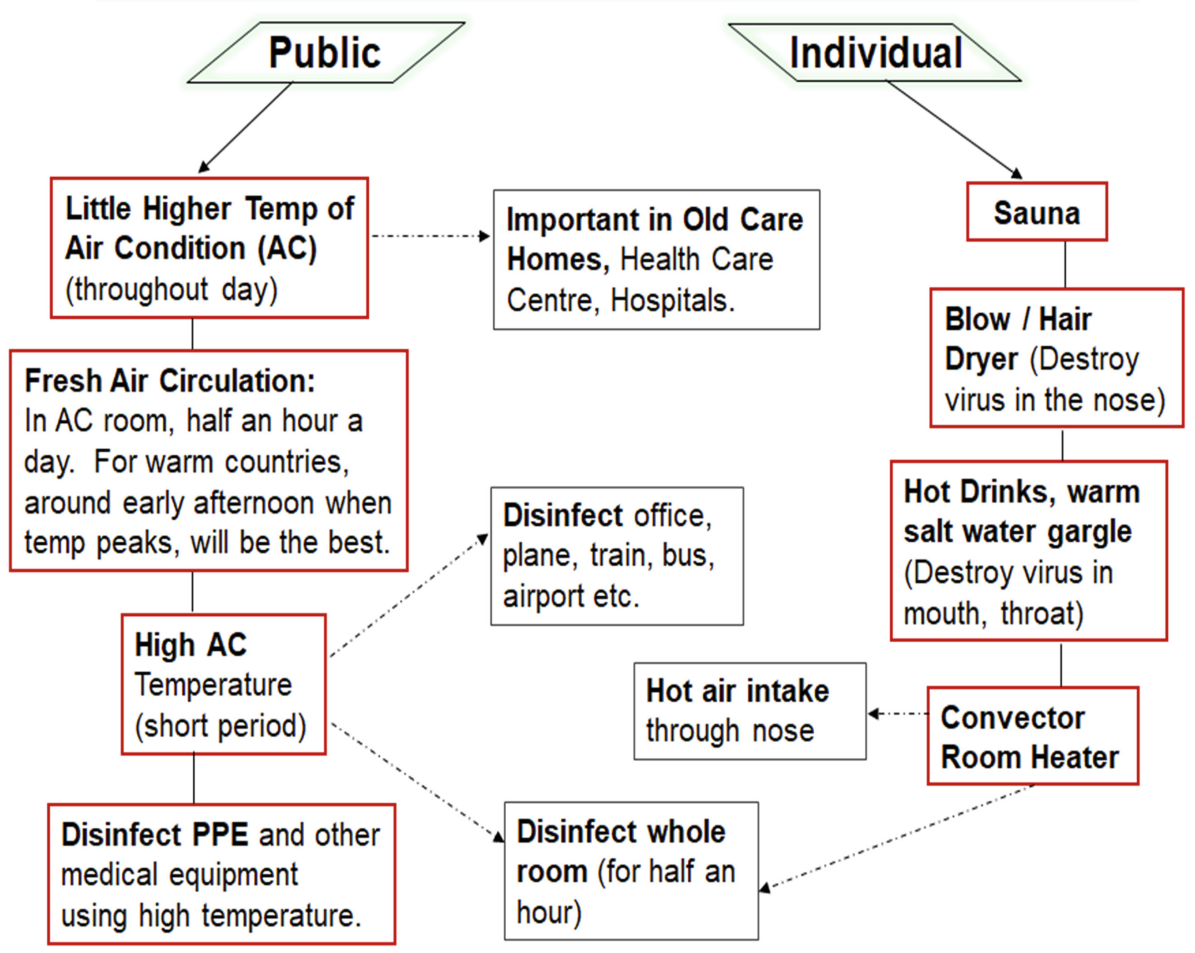

Fig. 6. An overview in the form of a schematic, depicting actions towards solutions at the public level (left) and individual level (right). (Roy, 2020, [29-31]).

levels if the temperature was simply raised to $20^{\circ} \mathrm{C}$ from $4{ }^{\circ} \mathrm{C}$; which is more rapid if the temperature was further increased to $40^{\circ} \mathrm{C}$ from $20^{\circ} \mathrm{C}$. However, contact transmission is still possible at high temperatures and lab experiments with guinea pigs showed contact transmission takes place even at $30{ }^{\circ} \mathrm{C}$ temperature [36]. In typical Air-Conditioning (AC) environments, which has room temperature $22-25^{\circ} \mathrm{C}$ and relative humidity (4050)\%, SARS can be active for at least five days [35].

The influence of temperature on the COVID-19 virus at global scale [29-33] and results of previous clinical trials with similar viruses that showed the strong dependency on temperature [34-38] provided a useful insight that regulating the level of temperature can offer remarkable results to stop and arrest the outbreak. Based on that knowledge, some urgent and simple heat-based solutions were proposed as early as $17^{\text {th }}$ March 2020 $[39,40]$, which are practically without side effects, no vested interest involved and very cost-effective too [Fig. 5, Fig. 6]. These measures at the initial stages of the disease are proposed because the virus, which is very sensitive to temperature, mainly accumulates at high volume in the nose and back of the mouth. Testing is done with swabs from backs of the mouth and nasal cavity. High temperature can reduce viral loads in those places and thus, the body will have strengths and time to defend against the disease easily. 
Successful clinical trial experiments following heat-based solutions to reduce transmission of COVID-19 were conducted and published [41] after receiving approval from the ethical committee. A thorough literature review in support of heat-based solutions to fight COVID-19 was also published in a peer-reviewed journal [42]. Being a medical doctor, the author discussed various mechanisms involved in the biological processes [42].

If these simple heat-based solutions at the initial stages of the disease [Fig. 5] become popular then people and government do not need to worry about mutated variants, long COVID, losing immunity after six months and further lockdown etc.

Competing Interest Statement. This study did not receive any funding and there is no financial interest. The first version was submitted to journal on $11^{\text {th }}$ March 2021, and preprint is [43] https:// doi.org/10.22541/au.161642232.28976638/v1 and [44] https://doi.org/10.22541/au.162584191. $11801390 / \mathrm{v} 1$.

\section{References}

1. Website: BBC. https://www.bbc.co.uk/news/uk-55227325. Accessed 6 Mar 2021

2. Website: Ourworldindata. https://ourworldindata.org/coronavirus-data-explorer. Accessed 9 Mar 2021

3. Website: Worldometers. https://www.worldometers.info/coronavirus/country/

4. Mallapaty, S.: Vaccines are curbing COVID: data from Israel show drop in infections. Nature 590, 197 (2021). https://doi.org/10.1038/d41586-021-00316-4

5. Website: Israelnationalnews, 18 February 2021. https://www.israelnationalnews.com/News/ News.aspx/297051

6. Website: Medicalxpress. https://medicalxpress.com/news/2020-12-uae-covid-vaccinationscapital.html. Accessed 8 Mar 2021

7. Website: Vaccine Adverse Event Reporting System (VAERS), Government website. https:// vaers.hhs.gov/resources/govtsites.html

8. Website: The Epoch Times. https://www.theepochtimes.com/adverse-incident-reports-show966-deaths-following-vaccination-for-covid-19_3723384.html. Published 6 Mar 2021, Updated 10 Mar 2021, Accessed 14 Mar 2021

9. Website CDC. https://www.cdc.gov/coronavirus/2019-ncov/vaccines/safety/adverse-events. html

10. Website: Indian Express. https://indianexpress.com/article/explained/explained-post-vaccin ation-effects-deaths-reading-the-data-available-so-far-7266875/. Accessed 13 Apr 2021

11. Website: The Guardian. https://www.theguardian.com/world/2021/apr/07/what-do-i-needto-know-about-the-oxfordastrazeneca-vaccine. Accessed 12 Apr 2021

12. Doshi, P.: Covid-19 vaccine trial protocols released a rare opportunity for public scrutiny of these key trials. BMJ 371, m4058 (2020). https://doi.org/10.1136/bmj.m4058

13. Doshi, P.: Will covid-19 vaccines save lives? Current trials aren't designed to tell us. BMJ 371, m4037 (2020). https://doi.org/10.1136/bmj.m4037. https://www.bmj.com/content/371/ bmj.m4037. https://www.bmj.com/company/newsroom/covid-19-vaccine-trials-cannot-tellus-if-they-will-save-lives/

14. Doshi, P.: BMJ, Rapid Response (2021). https://www.bmj.com/content/371/bmj.m4037/rr-23

15. Godlee, F.: Covid-19: we need new thinking and new leadership BMJ (2020). https://www. bmj.com/content/371/bmj.m4358 
16. Website: CDC. https://www.cdc.gov/flu/about/burden-averted/2017-2018.htm. Accessed 6 Mar 2021

17. Website: American Society for Microbiology. https://asm.org/Articles/2020/July/COVID-19and-the-Flu. Accessed 6 Mar 2021

18. Website: King Abdullah University of Science and Technology. https://www.cbrc.kaust.edu. sa/covmt/. Accessed 6 Mar 2021

19. Website: The Guardian, Published 8 February 2021. https://www.theguardian.com/world/ 2021/feb/08/oxford-covid-vaccine-10-effective-south-african-variant-study

20. Sanders, R.W.: Pandemic moves and countermoves: vaccines and viral variants. Lancet 397(10282), 1326-1327 (2021). https://doi.org/10.1016/S0140-6736(21)00730-3

21. Dailymail. https://www.dailymail.co.uk/health/article-9441695/Three-people-MichiganDIED-contracting-COVID-19-despite-fully-vaccinated.html. Accessed 13 Apr 2021

22. Website: BBC, 20 November 2020. https://www.bbc.co.uk/news/health-55022287

23. Website: The Guardian, Published 30 November 2018. https://www.theguardian.com/society/ 2018/nov/30/excess-winter-deaths-in-england-and-wales-highest-since-1976

24. Website: The Guardian, Published 7 April 2016. https://www.theguardian.com/uk-news/ 2016/apr/07/number-deaths-england-wales-12-year-high-life-expectancy

25. Alam, I., et al.: CovMT: an interactive SARS-CoV-2 mutation tracker, with a focus on critical variants. Lancet Infect. Dis. 2021. https://doi.org/10.1016/S1473-3099(21)00078-5. ISSN 1473-3099. https://www.sciencedirect.com/science/article/pii/S1473309921000785

26. Website: npj. 2021, Vaccines Could Add Fuel To Evolution Of Coronavirus Mutations, Published 10 February 2021. https://www.npr.org/sections/health-shots/2021/02/10/965940914/ covid-19-vaccines-could-add-fuel-to-evolution-of-more-coronavirus-mutation

27. Muller, C.P.:Do asymptomatic carriers of SARS-COV-2 transmit the virus? Lancet Regional Health - Europe, 2021, 4, May, 2021, 100082, ISSN 2666-7762, doi.org/https://doi.org/10. 1016/j.lanepe. 2021.100082.

28. Keehner, et al.: SARS-CoV-2 infection after vaccination in health care workers in California. N. Engl. J. Med. (2021). https://doi.org/10.1056/NEJMc2101927

29. Roy, I.: The role temperature on the global spread of COVID-19 and urgent solutions. Int. J. Environ. Sci. Technol. 18(9), 2903 (2020). https://doi.org/10.1007/s13762-020-02991-8

30. Website AGU: Roy, I. Influence of Temperature on the global spread of COVID-19 invited presentation, August 2020. https://agu2020fallmeeting-agu.ipostersessions.com/Default.aspx? s=4F-D9-45-B2-4C-B0-2A-F4-10-B5-71-05-DA-1D-45-4D. Accessed 27 July 2021

31. Roy, I.: Influence of temperature on the global spread of COVID-19 (2020). https://doi.org/ 10.22541/au.159301639.90704061/v2

32. Paulo, M., Travassos, d.R.M.B.R., Carlos, R.V.A., David, N.: Effects of temperature and humidity on the spread of COVID-19: a systematic review. Plos One. (2020). https://doi.org/ 10.1371/journal.pone.0238339

33. Scafetta, N.: Distribution of the SARS-CoV-2 pandemic and its monthly forecast based on seasonal climate patterns. Int. J. Environ. Res. Public Health 17(10), 3493 (2020). https://doi. org/10.3390/ijerph17103493

34. Van Doremalen, N., et al.: Stability of Middle East respiratory syndrome coronavirus (MERS$\mathrm{CoV}$ ) under different environmental conditions. Euro Surveill. 18(38), 20590 (2013). https:// doi.org/10.2807/1560-7917.ES2013.18.38.20590

35. Chan, K.H., Malik Peiris, J.S., Lam, S.Y., Poon, L.L.M., Yuen, K.Y., Seto, W.H.: The effects of temperature and relative humidity on the viability of the SARS coronavirus. Adv. Virol. 2011, Article ID 734690, 7 p. (2011). https://doi.org/10.1155/2011/734690

36. Lowen, A.C., et al.: Influenza virus transmission is dependent on relative humidity and temperature. PLoS Pathog. 3(10), 1470-1476 (2007). https://doi.org/10.1371/journal.ppat.003 0151 
37. Casanova, L., et al.: Effects of air temperature and relative humidity on coronavirus survival on surfaces. Appl Environ Microbiol. 76(9), 2712-2717 (2010)

38. Kim, S.W., Ramakrishnan, M.A., Raynor, P.C., Goyal, S.M.: Effects of humidity and other factors on the generation and sampling of a coronavirus aerosol. Aerobiologia 23(4), 239-248 (2007). https://doi.org/10.1007/s10453-007-9068-9

39. Roy, I.: Combating recent pandemic of COVID-19 - an urgent solution. (2020). https://doi. org/10.13140/RG.2.2.22632.83208. 17 March 2020

40. Roy, I.:Atmospheric variables and additional urgent solutions for combating COVID-19 (2020). https://www.preprints.org/manuscript/202003.0366/v2. https://www.researchgate. net/publication/340552840_Atmospheric_Variables_and_Additional_Urgent_Solutions_ for_Combating_COVID-19.9 April 2020

41. Marca, G.L., et al.: Thermal inactivation of SARS COVID-2 virus: are steam inhalations a potential treatment? Life Sci. 265, 118801 (2021) https://doi.org/10.1016/j.lfs.2020.118801. ISSN 0024-3205

42. Cohen, M.: Turning up the heat on COVID-19: heat as a therapeutic intervention, F1000Research (2020). pubmed.ncbi.nlm.nih.gov/32742639/

43. Roy, I.: 2021 COVID-19 crisis -exit strategy: part 1-exploring pathways of vaccination (2021). https://doi.org/10.22541/au.161642232.28976638/v1

44. Roy, I.: 2021 Exit strategy from COVID-19: vaccination and an alternative solution (2021). https://doi.org/10.22541/au.162584191.11801390/v1 